\title{
Comparação econômica entre os sistemas construtivos: alvenaria estrutural e concreto armado
}

\section{Economic comparison between building systems: structural masonry and reinforced concrete}

\author{
Isabela Cristina da Silva'; Angelo Rubens Migliore Junior ${ }^{2}$ \\ ${ }^{1}$ Curso de Especialização em Engenharia de Estruturas do Centro Universitário da Fundação Educacional de \\ Barretos, Unifeb. \\ ${ }^{2}$ Professor Doutor do curso de Engenharia Civil do Centro Universitário da Fundação Educacional de \\ Barretos, Unifeb.
}

\section{Resumo}

Este trabalho realizou um estudo comparativo entre dois sistemas construtivos: a alvenaria estrutural e o concreto armado. Para isso, utilizou-se, como metodologia, uma pesquisa bibliográfica, incluindo dois estudos que mostraram os orçamentos desses dois sistemas construtivos, sendo um da construtora MZM, de São Paulo, em 2013, relacionado a um projeto com 21 andares e 16 apartamentos em cada andar, totalizando 330 apartamentos e abrangendo uma área total de $7.556 \mathrm{~m}^{2}$, com $26.828,345 \mathrm{~m}^{2}$ de área construída. $\mathrm{O}$ outro, da Cohab de Santa Catarina, em 2017, referente a um projeto padrão de uma residência unifamiliar, da mesma forma que é utilizada em programas de habitação social. Os resultados mostraram que, nos dois trabalhos apresentados, a alvenaria estrutural se apresentou economicamente mais viável. No estudo da construtora MZM, o custo total de material e mão de obra foi de R $\$ 7.166 .854,83$ para o concreto armado e R\$ 6.078.222,34 para a alvenaria estrutural, apresentando uma diferença de R\$1.088.632,49, enquanto no orçamento da Cohab de Santa Catarina o custo total só de material foi de $\mathrm{R} \$ 30.728,49$ para o concreto armado e de R $\$ 21.400,71$ para a alvenaria estrutural, apresentando uma diferença de R\$ 9.327,77.

Palavras-chave: alvenaria estrutural, concreto armado, custos.

\begin{abstract}
This work aimed to make a comparative study between two building systems: structural masonry and reinforced concrete. For this, bibliographic research was used as methodology, including two studies that showed the budgets of these two building systems, one of the construction company MZM, from São Paulo, in 2013, related to a project with 21 floors and 16 apartments on each floor, totaling 330 apartments and covering a total area of 7,556 $\mathrm{m}^{2}$, with $26,828.345 \mathrm{~m}^{2}$ of built area. The other, from Cohab de Santa Catarina, 2017 , refers to a standard project of a single-family residence, as it is used in social housing programs. The results showed that in both works presented, the structural masonry was economically more viable. In the study by MZM, the total cost of material and labor was R $\$ 7,166,854.83$ for reinforced concrete and $\mathrm{R} \$ 6,078,222.34$ for structural masonry, with a difference of $\mathrm{R} \$ 1,088.632 .49$, while in the Cohab budget of Santa Catarina the total material cost alone was $\mathrm{R} \$ 30,728.49$ for reinforced concrete and $\mathrm{R} \$ 21,400.71$ for structural masonry, with a difference of $\mathrm{R} \$ 9,327.77$.
\end{abstract}

Keywords: Structural masonry. Reinforced concrete. Costs.

\footnotetext{
Autor para correspondência: rubens.migliore@unifeb.edu.br

Recebido para publicação: 19/11/2019

Aceito para publicação: 27/10/2020
}

https://doi.org/10.4322/1980-0029.112019 


\section{Introdução}

No Brasil, a Construção Civil vivencia um cenário de busca por mais produtividade, desenvolvimento de inovações, mais racionalização, mais padronização e elevação de escala, menos custos e sustentabilidade (Agência Brasileira de Desenvolvimento Industrial, 2016).

Além desses fatores, a Construção Civil brasileira tem se esforçado também para elevar seus níveis de planejamentos físicos e econômicos, melhorar a qualificação do trabalhador, reduzir seus índices de desperdícios, aumentar a qualidade e diminuir as incidências de manifestações patológicas, enfim, elevar, de forma geral, o seu desempenho. Esse esforço se deve à demanda de habitações, que tem aumentado expressivamente por conta dos incentivos do governo federal (Teixeira, 2015).

Dados de uma pesquisa realizada pela Associação Brasileira de Incorporadoras Imobiliárias (Abrainc) em parceria com a Fundação Getúlio Vargas (FGV) informam que o Brasil bateu o recorde de déficit habitacional, o qual apresentou aumento de $7 \%$, entre o período de 2007 e 2017, sendo necessários 7,78 milhões de moradias para atender a esse déficit (Rede Brasil Atual, 2019).

Este é o grande desafio vivenciado pelo país no momento, exigindo urgência na busca por sistemas construtivos mais ágeis e baratos, pois a tendência é de aumento desse déficit habitacional.

Levando-se em consideração a urgência de sistemas construtivos mais racionalizados, que sejam executados mais rapidamente e com mais economia, necessário se faz desenvolver estudos para conhecer quais deles podem ser mais eficazes para suprir essa demanda habitacional, seja em termos técnicos, seja em termos econômicos.

Diante desse contexto, o principal objetivo deste trabalho foi verificar a comparação de um estudo entre dois sistemas construtivos: a alvenaria estrutural e o concreto armado, com o intuito de passar a ter mais conhecimento a respeito das características de ambos, bem como das vantagens e desvantagens em relação a tempo, custos e quantidade de mão de obra.

A alvenaria estrutural e o concreto armado são sistemas muito empregados na estrutura de edifícios e conjuntos habitacionais. São sistemas bem conhecidos no mercado e apresentam muita semelhança no sistema de resistências, dependendo de serem escolhidos conforme o tipo de projeto que se está realizando (Mapa da Obra, 2019).
A alvenaria estrutural é um sistema construtivo no qual as cargas são transmitidas às fundações por meio de planos verticais, a própria parede, de forma a dispensar o uso de vigas, pois as lajes se apoiam diretamente sobre as paredes (Pereira, 2016).

$\mathrm{O}$ sistema em concreto armado tem mais aplicação em estruturas reticuladas, constituídas por vigas e pilares. Assim, as paredes no interior dos imóveis são utilizadas apenas como vedação. Trata-se de uma solução encontrada, no passado, para unir a resistência à compressão e durabilidade da pedra com as características do aço, resultando em um material que pode assumir qualquer forma com rapidez e facilidade, proporcionando ao metal proteção contra a corrosão (AECweb, 2019).

A alvenaria estrutural é um processo construtivo no qual as paredes de alvenaria e as lajes enrijecedoras atuam estruturalmente para substituir pilares e vigas empregados em sistemas construtivos tradicionais, cujo dimensionamento é realizado por métodos de cálculos racionais e de determinável confiabilidade. Nesse sistema construtivo, as paredes se apresentam, simultaneamente, como subsistemas de estrutura e vedação, proporcionando mais simplicidade construtiva e elevado nível de racionalização (Roman \& Parizzoto Filho, 2019).

O sistema construtivo de alvenaria estrutural tem se expandido expressivamente no Brasil e também em todo o mundo, em razão de vantagens como flexibilidade construtiva, maior e mais agilidade na construção, além da sua maior característica, que é a racionalização e produtividade, tornando possíveis construções com elevado desempenho tecnológico, qualidade e economia.

A alvenaria do tipo estrutural é caracterizada por empregar blocos de concreto ou cerâmicos autoportantes. Tem a função de sustentar o peso da estrutura, não devendo ser confundida com alvenaria de vedação. A Figura 1 ilustra a alvenaria estrutural com blocos de concreto, ilustra a necessidade de compatibilização de projetos hidráulicos, elétricos e estrutural, uma vez que a alvenaria estrutural não permite modificações de layout nem rasgos para a passagem de conduítes elétricos ou canos hidráulicos, sendo aconselhável que toda a parte hidráulica da edificação seja feita fora dos blocos estruturais, sendo "escondida" através de sancas de gesso.

Os blocos podem ser vazados na vertical e, em edifícios com até quatro pavimentos, a alvenaria não precisa ser armada, porém, acima dessa 


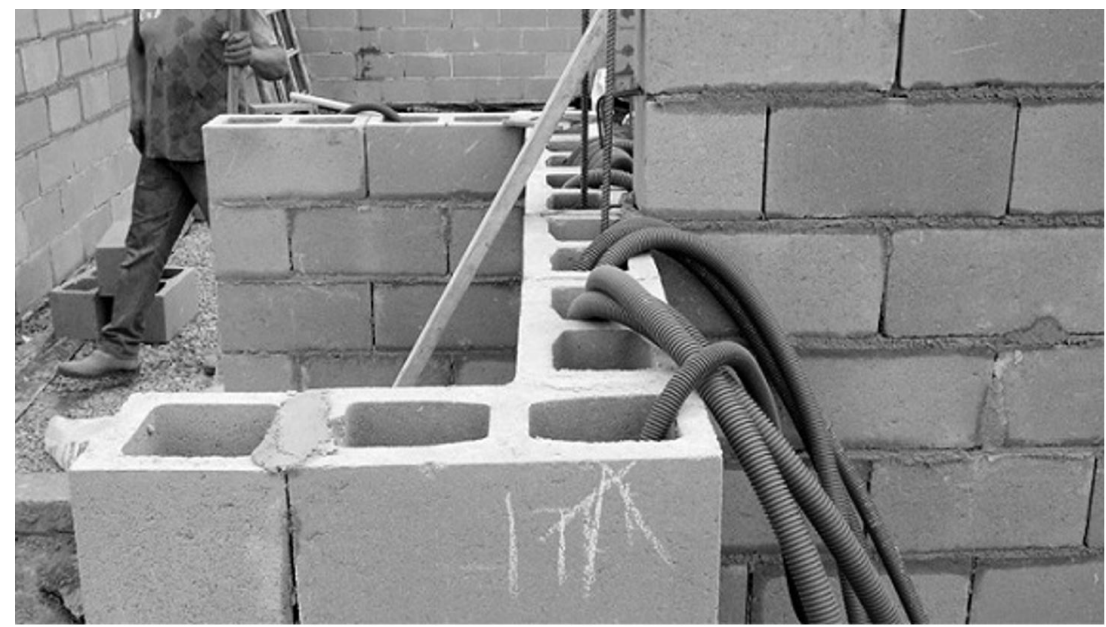

Figura 1. Alvenaria estrutural com blocos de concreto. Fonte: Escola de Engenharia (2019).

quantidade de pavimentos, é necessário que seja armada (Pereira, 2016).

A ABNT NBR 15961:2011 é a norma que traz especificações mínimas para um projeto de estrutura de alvenaria de blocos de concreto, bem como para a aplicação desse sistema com outros sistemas estruturais. A elaboração de um projeto de estrutura de alvenaria deve adotar o sistema estrutural adequado à função que se deseja na edificação e também executar ações que apresentem compatibilidade e representatividade, além de um adequado dimensionamento, da observação dos elementos estruturais presentes, dos materiais apropriados bem especificados (Mapa da Obra, 2019).

O concreto consiste em um material de elevada resistência às tensões de compressão e, sobretudo, apresenta baixa resistência à tração (aproximadamente 10\% da sua resistência à compressão). Desta forma, é necessário juntar ao concreto um material com alta resistência à tração, com a finalidade de resistir às tensões de tração atuantes. Portanto, a partir desse material constituído por concreto e armadura - barras de aço, surge o concreto armado, cujas barras da armadura têm a função de absorver as tensões de tração, enquanto o concreto absorve as tensões de compressão (Associação Brasileira de Normas Técnicas, 2014).

Entretanto, no conceito de concreto armado ainda se encontra envolvido o fenômeno da aderência, que é fundamental, devendo ser obrigada a existir entre o concreto e a armadura, não sendo suficiente somente juntar os dois materiais para que se constitua o concreto armado. Para que surja o concreto armado propriamente dito, é necessário haver uma efetiva solidariedade entre o concreto e o aço e que o trabalho seja realizado conjuntamente.

Portanto, conceitua-se concreto armado como a junção do concreto simples com um material resistente à tração, o qual deve ser envolvido pelo concreto, de forma que ambos, juntos, possam resistir solidariamente aos esforços solicitados (AECweb, 2019).

A Figura 2 ilustra uma viga em concreto armado. A disposição e a dimensão das vigas e pilares depende das solicitações e da adequação ao projeto arquitetônico. A quantidade de vergalhões e o volume de concreto devem atender a cálculos estruturais.

Quanto às vantagens e desvantagens dos dois tipos de sistemas construtivos, estas são apresentadas a seguir, conforme a Escola de Engenharia (2019): i) a alvenaria estrutural apresenta consumo reduzido de formas de madeira, aço e concreto; ii) obra construída mais rapidamente; custo reduzido em relação ao sistema convencional de vigas, pilares e lajes; mais fácil o treinamento de mão de obra; iii) canteiro de obra mais organizado; iv) o concreto armado apresenta como vantagens elevada resistência à compressão em comparação a outros materiais de construção; v) devido à armação, esse material estrutural também pode suportar uma boa quantidade de esforços de tração; vii) o custo de manutenção do concreto armado é muito baixo; 


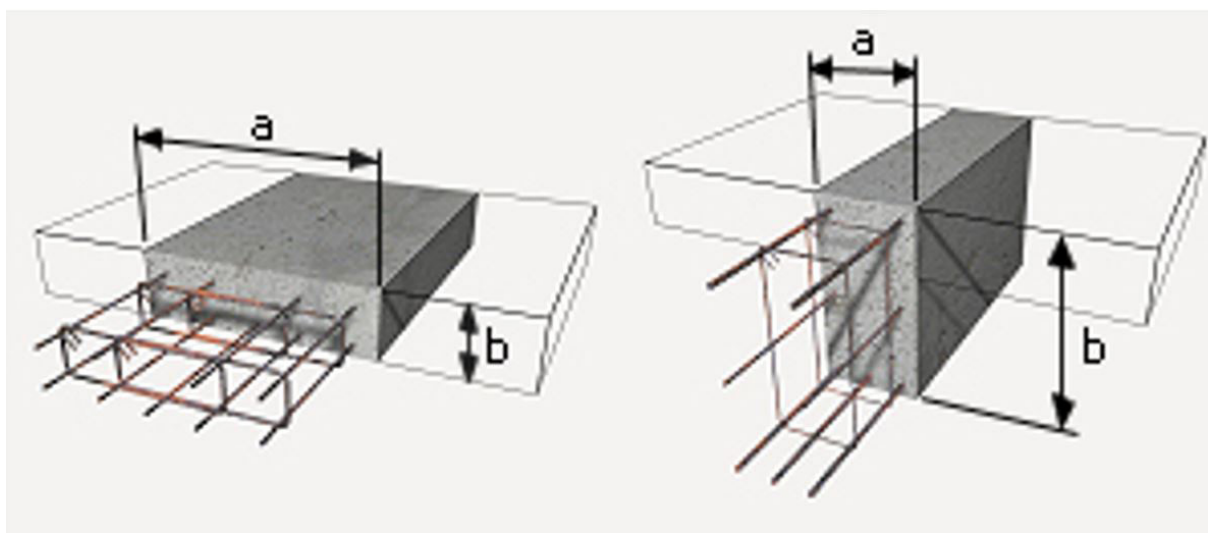

Figura 2. Viga em concreto armado. Fonte: Moura (2019).

vii) a estrutura em armado pode ser moldada de diversas maneiras e formatos; viii) demanda por mão de obra menos qualificada para sua execução; ix) apresenta boa resistência ao fogo, ao tempo e também ao desgaste mecânico, como choques e vibrações; $\mathrm{x}$ ) mais durável do que qualquer outro sistema de construção.

Em relação às desvantagens, a alvenaria estrutural apresenta limitação em sua arquitetura e design, devido ao tamanho e à forma dos blocos estruturais; em casos de ser necessário derrubar uma parede, é preciso o aval de um engenheiro, pois a estrutura pode ruir, caso ocorra sua retirada sem os devidos cuidados; o concreto armado apresenta as seguintes desvantagens: possui cerca de um décimo de resistência à tração em relação à compressão; por ser muitas vezes produzido in loco, a resistência final pode ser afetada devido a erros durante os processos de mistura e cura; faz uso de formas de madeira ou metálicas, o que acaba elevando os custos do projeto; gera muitos resíduos e lixos de construção; para se construir um edifício de vários andares, a seção dos pilares para uma estrutura em "armado" é maior do que a seção dos pilares em uma estrutura metálica; o concreto armado tem grande peso próprio $\left(2.500 \mathrm{~kg} / \mathrm{m}^{3}\right)$; o tempo de execução se apresenta maior do que outros sistemas de construção devido ao tempo de cura (pode ser reduzido com o uso de aditivos); a demolição de uma estrutura em concreto armado é de difícil execução, podendo ser inviável devido ao custo (Escola de Engenharia, 2019).

A Construção Civil tem caminhado em direção à industrialização e à melhora dos sistemas construtivos. Métodos tradicionais estão se mostrando menos produtivos e com qualidade inferior, ao serem comparados com sistemas industrializados. Sobretudo, é necessário que sejam analisados vários fatores, antes da escolha por um sistema construtivo, entre eles a mão de obra, os custos, a durabilidade, o objetivo e a função da construção (Pereira, 2019).

\section{Material e métodos}

$\mathrm{O}$ método empregado na realização desse trabalho foi uma pesquisa bibliográfica, com a obtenção dos dados em sites técnicos, livros, trabalhos de conclusão de curso e artigos científicos, sobre a diferença e as vantagens e desvantagens dos sistemas construtivos de alvenaria estrutural e de concreto armado.

Para comparar economicamente os dois sistemas construtivos, de alvenaria estrutural e de concreto armado, apresenta-se um orçamento realizado pela MZM construtora e incorporadora que, em 2013, construiu um edifício na região de Mauá (SP).

O projeto foi elaborado com 21 andares e 16 apartamentos em cada andar, totalizando 330 apartamentos e abrangendo uma área total de $7.556 \mathrm{~m}^{2}, \operatorname{com} 26.828,345 \mathrm{~m}^{2}$ de área construída.

Apresenta-se também outro projeto, o qual comparou os custos de produção de dois sistemas construtivos, alvenaria estrutural e de concreto armado, utilizando-se um projeto padrão de uma residência unifamiliar, da mesma forma que é utilizada em programas de habitação social, realizado pela Companhia de Habitação de Santa Catarina (COHAB-SC), tratando-se de uma construção térrea, com sala, três quartos, banheiro, cozinha 
Tabela 1. Custos orçados pela construtora MZM (2013)

\begin{tabular}{lcc}
\hline \multicolumn{1}{c}{ Custos } & Concreto armado & Alvenaria estrutural \\
\hline Custo total do material & $\mathrm{R} \$ 4.306 .127,05$ & $\mathrm{R} \$ 3.693 .386,18$ \\
Custo total de mão de obra & $\mathrm{R} \$ 2.860 .727,78$ & $\mathrm{R} \$ 2.384 .836,18$ \\
Custo total & $\mathrm{R} \$ 7.166,854.83$ & $\mathrm{R} \$ 6.078 .222,34$ \\
\hline
\end{tabular}

Fonte: Silva et al. (2017)

Tabela 2. Custos orçados pela COHAB SC (2017)

\begin{tabular}{lcc}
\hline \multicolumn{1}{c}{ Sistema } & Concreto armado & Alvenaria estrutural \\
\hline Superestrutura & $\mathrm{R} \$ 11.531,74$ & $\mathrm{R} \$ 11.258,85$ \\
Vedação & $\mathrm{R} \$ 9.054,89$ & - \\
Revestimentos & $\mathrm{R} \$ 10.141,86$ & $\mathrm{R} \$ 10.141,86$ \\
Custo total & $\mathrm{R} \$ 30.728,49$ & $\mathrm{R} \$ 21.400,71$ \\
Custo diferencial & $\mathrm{R} \$ 0,00$ & $\mathrm{R} \$ 9.327,77$ \\
Variação (\%) & $100,0 \%$ & $-30,35 \%$ \\
\hline
\end{tabular}

Fonte: Jesus (2018).

e área de serviço, com pé direito de 2,4 metros, totalizando uma área de $48 \mathrm{~m}^{2}$.

Os custos foram compostos utilizando a Tabela do Sistema Nacional de Pesquisa de Custos e Índices da Construção Civil, não desonerada, com valores referentes a 2018 para o estado de Mato Grosso.

\section{Resultados}

O orçamento oferecido pela Construtora MZM, em 2013, resultou nos valores apresentados na Tabela 1.

De acordo com esses dados, a construtora MZM considera que, economicamente, a alvenaria estrutural se apresentou melhor, cerca de $15 \%$ mais barata que o concreto armado e $20 \%$ mais rápida em sua execução.

Os resultados do estudo apresentado pela COHAB-SC estão apresentados na Tabela 2.

Os resultados mostraram que o sistema de alvenaria estrutural apresentou menores custos em comparação com concreto armado, portanto corroborando os resultados de Silva et al. (2017).

\section{Conclusão}

Nos dois trabalhos apresentados, a alvenaria estrutural se apresentou economicamente mais viável. No estudo da construtora MZM, o custo total de material e mão de obra foi de $\mathrm{R} \$ 7.166,854,83$ para o concreto armado e de $\mathrm{R} \$ 6.078 .222,34$ para a alvenaria estrutural, apresentando uma diferença de R\$1.088.632,49, enquanto no orçamento da Cohab de Santa Catarina o custo total só de material foi de $\mathrm{R} \$ 30.728,49$ para o concreto armado e de $\mathrm{R} \$$
21.400,71 para a alvenaria estrutural, apresentando uma diferença de $\mathrm{R} \$ 9.327,77$.

\section{Referências}

AECweb. (2019). Concreto armado é solução durável e econômica. Recuperado em 23 de outubro de 2019, de https://www.aecweb.com.br/ cont $/ \mathrm{m} / \mathrm{rev} /$ concreto-armado-e-solucao-duravele-economica_6993_10_0

Agência Brasileira de Desenvolvimento Industrial - ABDI. (2016). Estudo panorama da construção civil. Brasília. Recuperado em 21 de outubro de 2019, de https://old.abdi.com.br/Estudo/ Panorama\%20 Setorial $\% 20 \mathrm{de} \% 20$ Constru $\% \mathrm{C} 3 \% \mathrm{~A} 7 \% \mathrm{C} 3 \% \mathrm{~A} 30 \% 20$ Civil.pdf

Associação Brasileira de Normas Técnicas ABNT. (2014). NBR 6118: projeto de estruturas de concreto: procedimento. Rio de Janeiro: ABNT.

Escola de Engenharia. (2019). Alvenaria estrutural: vantagens e desvantagens. Recuperado em 20 de outubro de 2019, de https://www.escolaengenharia. com.br/alvenaria-estrutural/

Jesus, A. (2018). Análise comparativa dos sistemas construtivos em alvenaria convencional, alvenaria estrutural e moldes isolantes para concreto (Icf). E\&S Engineering and Science, 7(3), 12-27.

Mapa da Obra. (2019). Alvenaria estrutural $\times$ concreto armado: descubra as diferenças. Recuperado em 20 de outubro de 2019, de https:// www.mapadaobra.com.br/capacitacao/alvenariaconcreto-armado/ 
Moura, J. (2019). Dimensionamento de vigas de concreto: aplicações. Guia da Engenharia. Recuperado em 28 de outubro de 2019, de https:// www.guiadaengenharia.com/dimensionamentovigas-concreto-aplicacoes/

Pereira, C. (2016). Alvenaria estrutural: vantagens e desvantagens. Escola Engenharia. Recuperado em 21 de outubro de 2019, de https://www. escolaengenharia.com.br/alvenaria-estrutural/

Pereira, C. (2019). O que é concreto armado? Escola de Engenharia. Recuperado em 20 de outubro de 2019, de https://www.escolaengenharia.com.br/ concreto-armado/

Rede Brasil Atual. (2019). Déficit habitacional bate recorde e movimentos veem futuro com preocupação. Recuperado em 19 de outubro de 2019, de https://www.redebrasilatual.com.br/

Roman, H.; Parizzoto Filho, S. (2019). Manual de alvenaria estrutural com blocos cerâmicos. Recuperado em 28 de outubro de 2019, de https://www.docsity.com/pt/manual-alvenariaestrutural/4796410/

Silva, D. B. M., Sales, F. M., Silva, L. A., \& Silva, M. S. (2017). Análise comparativa entre alvenaria estrutural e concreto. Revista Educação, Meio Ambiente e Saúde, 7(4), 103-118.

Teixeira, C. C. (2015). Programa Minha Casa Minha Vida Faixa 1- FAR - Empresas, e Programa Minha Casa Minha Vida Faixa 1- FDS - Entidades, dois programas e duas políticas. In Anais do $3^{\circ}$ CHIEL. São Paulo: FAU-USP. 